\title{
Nuevas noticias sobre Alfonso de Pinos, un ensamblador oaxaqueño de la primera mitad del siglo XVIII
}

\section{New News about Alfonso de Pinos, an Oaxacan Assembler from the First Half of the I8th Century}

Artículo recibido el 2I de junio de 2020; devuelto para revisión el 3I de agosto de 2020; aceptado el Io de octubre; https://doi.org/IO.2220I/iie.I8703062e.2021.II8.2746.

Edén Zárate Universidad Nacional Autónoma de México-Instituto de Investigaciones Estéticas, ce_eden@yahoo.com.mx, https://orcid.org/ oooo-oooI-7360-8744.

Líneas de investigación Cabildo Catedral novohispano; arte novohispano.

Lines of research New Spain; Cathedral Chapter; Novo-Hispanic art.

Publicación más relevante "La reforma disciplinaria de la capilla musical de la Catedral Metropolitana durante la segunda mitad del siglo xviII. El caso del chantre Juan Ignacio de la Rocha. I768-I77I", en Actores del ritual en la Catedral de México (México: Universidad Nacional Autónoma de México-Instituto de Investigaciones Estéticas, 2016).

Resumen El texto aborda la vida de un carpintero oaxaqueño de la primera mitad del siglo xvin llamado Alfonso de Pinos. A partir de nuevas noticias documentales, se reconstruye parte de su genealogía y se muestra cómo se entrelaza con la de Tomás de Sigüenza, uno de los doradores y ensambladores de Oaxaca más importantes de finales del siglo xviı y primeras décadas del xviII. Se propone que el vínculo familiar entre ambos permitió el aprendizaje del oficio y las recomendaciones para laborar en algunos templos en dicha ciudad, pero sobre todo en la Catedral de Oaxaca.

Palabras clave Carpinteros; doradores; ensambladores; genealogía; catedral de Oaxaca.

Abstract This article addresses the life of the eighteenth-century Oaxacan carpenter Alonso de Los Pinos. It offers a reconstruction of the craftsman's family history through documentary evidence that demonstrates a close connection with Tomás de Sigüenza, one of the most relevant gilders and altarpiece assemblers living in Oaxaca during the late seventeenth and the early eighteen century. Moreover, the article proposes 
that the family bond between these two men encouraged their learning of their respective trades and enabled them to recommend each other for works in different churches of the city, especially in Oaxaca Cathedral.

Keywords Carpenters; gilders; altarpiece assemblers; genealogy; Oaxaca cathedral. 
DOI: https://doi.org/10.22201/iie.18703062e.2021.118.2746

\author{
EDÉN ZÁRATE
}

INSTITUTO DE INVESTIGACIONES ESTÉTICAS, UNAM

\title{
Nuevas noticias sobre Alfonso de Pinos,
}

un ensamblador oaxaqueño de la primera mitad
del siglo XVIII

1 templo de Nuestra Señora de las Nieves, en el centro histórico de la ciu$\checkmark$ dad de Oaxaca, se yergue como testigo mudo de la labor de uno de los artistas que, debido a su muerte prematura, no pudo prolongar su obra artística. Me refiero a Alfonso de Pinos, quien también trabajó para otros templos de la misma ciudad entre I7I4 y $1735 .{ }^{\mathrm{I}}$ De su obra nada permanece, pero sabemos que se le contrató por las escrituras que firmó con distintas personas. Parte de su vida la he podido reconstruir gracias a la memoria testamentaria que otorgó el I de diciembre de 1735 ante escribano real y público. ${ }^{2}$

Estas líneas, apoyadas en el testamento y otros documentos resguardados en distintos archivos del estado de Oaxaca, pretenden aportar más noticias no sólo de su vida y de su obra, sino también de su relación familiar con Tomás de Sigüenza, uno de los grandes artistas oaxaqueños de las últimas décadas del siglo XVII y primera del XVIII, y de quien Heinrich Berlin rastrea su genealogía en los primeros años del siglo XVII en Guatemala. ${ }^{3}$

I. Fátima Halcón fue la primera en posar la mirada sobre este artífice, véase Fátima Halcón, "Oaxaca: noticias de artistas I680-I780", Archivo Español de Arte LXXI, núm. 282 (abril-junio de 1998): I37-I5O.

2. Archivo Histórico de Notarías del Estado de Oaxaca (en adelante AHNeo), escribano: Manuel Álvarez de Aragón, núm. de inv. Io, I de diciembre de I735, ff. I68-I69v.

3. Heinrich Berlin, Historia de la imaginería colonial en Guatemala (Guatemala: Editorial del Ministerio de Educación Pública, 1970), I66. 


\section{DOI: https://doi.org/10.22201/iie.18703062e.2021.118.2746}

232

EDÉN ZÁRATE

\section{La familia de Alfonso de Pinos}

El primero de diciembre de 1735, Alfonso de Pinos yacía sobre su cama y con las pocas fuerzas que le quedaban ponía su firma en la memoria testamentaria que su hermano, el bachiller Santiago de Pinos, a su nombre, dictaría unos meses después a un escribano. ${ }^{4}$ De acuerdo con dicha memoria, era originario y vecino de la ciudad de Oaxaca; hijo de Domingo de Pinos y de Catarina de Ávila Cortés, ${ }^{5}$ ambos difuntos; tenía tres hermanos: los cirujanos Luis y Santiago, ${ }^{6}$ y Antonia Francisca. ${ }^{7}$

El 9 de febrero de 1705 contrajo primeras nupcias con María de Sigüenza, hija del ensamblador y dorador Tomás de Sigüenza y de Francisca Rendón. ${ }^{8}$ En su testamento declaró que durante "los I2 años" en los que estuvo casado con María, procreó dos hijas: Francisca y Dominga. ${ }^{9}$ Es importante mencionar que, al cotejar esta información con los libros de defunciones en el Archivo de la Parroquia del Sagrario de la Catedral, se localizó el registro de la muerte de su esposa, acaecida el 2 de noviembre de $1710,{ }^{10}$ lo que me hace pensar que durante los días de su agonía, su memoria pudo estar débil, pues realmente sólo estuvo casado con María durante cinco años o, tal vez, al momento en que su hermano dictó el testamento, hubo un error al registrar el tiempo que duró el matrimonio. Los años que siguieron después de la muerte de su esposa

4. El poder para testar le fue otorgado a Santiago el I9 de noviembre de I735, véase: AHNEO, escribano: Manuel Álvarez de Aragón, núm. de inv. 50, I de diciembre de 1735, ff. 417v-420v.

5. Aunque Fátima Halcón menciona que fue hijo de Domingo de Pinos y Dalmira Cortés, el testamento me ha permitido aportar el nombre completo de sus padres, véase: Fátima Halcón, "Oaxaca: noticias de artistas", I44.

6. En una carta poder que otorga Santiago de Pinos a sus dos hermanos Alfonso y Luis, el 3 de enero de 172I, se menciona que tanto Santiago como Luis eran maestros de cirugía, véase: AHNEO, escribano: José de Araujo, lib. I23, f. I.

7. Contrajo nupcias con el herrero Basilio de Lara el 20 de diciembre de I7IO, Archivo de la Parroquia del Sagrario Metropolitano de la Diócesis de Oaxaca (en adelante APSMdo), Matrimonios, vol. 4, años: I708-I7II, f. 82.

8. APSMdo, Matrimonios, vol. 3, I70I-I708, f. II2. Es importante señalar que el párroco al registrar el nombre de nuestro ensamblador, lo hace "Juan Alfonso de Pinos", pero es la única ocasión que aparece de esta manera en nuestras fuentes.

9. Dominga Soriana fue bautizada el I8 de septiembre de 1708. Apsmdo, Bautizos, vol. 9, I708-I7II, f. 4I.

IO. APSMDo, Libros de defunciones, vol. 5, I710, f. I09. 
los dedicó a criar a sus dos hijas pequeñas, tarea que terminó cuando estuvieron listas para contraer nupcias.

Diez años después de haber quedado viudo, contrajo segundo matrimonio, con una mujer mestiza, curiosamente llevaba el mismo nombre y apellido de su primera esposa: María de Sigüenza, ${ }^{\text {II }}$ sólo que ésta era hija de Augustina de Sigüenza, de quien los datos no permiten establecer vínculo familiar con don Tomás de Sigüenza. ${ }^{\mathrm{I} 2}$ Durante este segundo matrimonio, de acuerdo con su memoria testamentaria, procreó siete hijos; no obstante, al revisar los libros de bautizos, se localizó otro hijo de Alfonso, fruto del mismo matrimonio, llamado José Manuel, bautizado el I8 de diciembre de $1726,{ }^{13}$ que tal vez por la poca lucidez de su memoria en sus últimos días o quizá por la muerte prematura del pequeño, no lo mencionó en su última voluntad. Los otros hijos fueron: María, Antonia, Santiago, Félix, ${ }^{14}$ María Ana, Josefa ${ }^{15}$ y Micaela. ${ }^{16}$

\section{Linaje de ensambladores}

El primer matrimonio de Pinos fue con María de Sigüenza, hija de Tomás de Sigüenza, uno de los artistas más importantes de Oaxaca, quien laboró en esa ciudad desde 1689 , en la factura de un sagrario para el retablo mayor de la iglesia del convento de San Francisco, hasta 1708 cuando compuso y doró el retablo mayor de la catedral de Oaxaca; ésta fue la última noticia de Sigüenza en la ciudad de Oaxaca, aunque Fátima Halcón localizó un rastro de Tomás en la Ciudad de México, cuando en 1730 se presentó como testigo para obtener el grado de bachiller en Teología de don Manuel José de Veitia. ${ }^{17}$

II. El matrimonio se realizó ante el bachiller Diego Gallegos el i3 de julio de 1720 y uno de sus testigos fue su hermano Santiago, APSMDo, Matrimonios, vol. 5, I717-1724, f. I96.

I2. Halcón sugiere que la segunda esposa es familiar de Tomás de Siguénza, véase: Halcón, "Oaxaca: noticias de artistas", I44.

I3. APSMDO, vol. I4, I724-I727, f. 263v. Cabe mencionar que en el poder para testar que Alfonso otorgó a su hermano Santiago, tampoco menciona a este hijo, véase nota 2.

I4. Bautizado el ro de julio de I729. APSMDO, vol. I6, I729-I732, f. 5 v.

I5. Bautizada con el nombre de Josefa María el i8 de abril de I732. APSMDo, vol. 16, I729I732, f. $248 \mathrm{v}$.

I6. Bautizada con el nombre de Micaela Francisca el 3 de octubre de I733, APSMDo, vol. I7, I732-I734, f. 75 .

17. Fátima Halcón, "Noticias sobre Tomás de Sigüenza en Oaxaca", Acervos, Boletín de los Archivos y Bibliotecas de Oaxaca, núm. I (1996): I3; Halcón, "Oaxaca: noticias de artistas", I43. 


\section{DOI: https://doi.org/10.22201/iie.18703062e.2021.118.2746}

Heinrich Berlin sugiere que Tomás fue quizá hijo de Juan de Sigüenza, maestro dorador y estofador con grado de alférez, y de María del Castillo ${ }^{18}$ y que pudo haber nacido alrededor de I667; si le damos crédito a este autor, podemos, por tanto, rastrear la genealogía de Tomás hasta finales del siglo XVI en Oaxaca; es decir, comienza cuando Bartolomé de Sigüenza, su esposa, e hijo — del mismo nombre que el padre, a quien llamaremos Bartolomé hijo, para distinguirlo del primero y de quien no existe hasta ahora noticia de que haya tenido relación con la fabricación de retablos-, se trasladan de la ciudad de Oaxaca a Guatemala en busca de nuevos horizontes (fig. I). Bartolomé hijo contrajo nupcias con María Contreras, de este matrimonio nació Cristóbal de Sigüenza; padre e hijo trabajaron juntos en I639 "dorando, estofando y matizando" un retablo para el pueblo de San Antonio en Guatemala; después Cristóbal, por su parte, trabajó al lado de Diego de Pineda en I660 en un retablo dedicado a Nuestra Señora del Carmen en el convento de la Concepción, también en Guatemala. Cristóbal contrajo nupcias con María García en I642 y procrearon a José de Sigüenza. ${ }^{19}$

Bartolomé hijo procreó con otra mujer, de la cual desconocemos su nombre, a un hijo ilegítimo a quien llamó Juan de Sigüenza, y ejerció el mismo oficio que su padre. De acuerdo con Jorge Luján, este último, en 1675 concertó el dorado del retablo mayor de la parroquia de Mixco, obra importante por "el tamańo de dicho poblado pokomam perteneciente al corregimiento del valle de Guatemala, relativamente a poca distancia de Santiago" ${ }^{20}$ En I68I hizo el dorado y estofado del retablo mayor de Huehuetenango; para 1685 doró y estofó el retablo mayor del convento de Santa Teresa y, entre i686 y I687, trabajó junto a su sobrino José de Sigüenza, hijo de su medio hermano Cristóbal, en el retablo mayor de San Juan Sacatepéquez. ${ }^{21}$ Juan contrajo nupcias con María del Castillo, con la que procreó varios hijos, de acuerdo con Berlin "uno de ellos llamado Tomás, tenía en 1687,20 años", ${ }^{22}$ quien, en fecha que desconocemos, se trasladaría a la ciudad de Oaxaca donde comenzaría sus labores artísticas. Más adelante se casaría con Francisca de Ulloa Rendón —hija

18. Heinrich Berlin, Historia de la imaginería, I66.

19. Berlin, Historia de la imaginería, I64-I67.

20. Jorge Luján Muñoz, "Algunos ejemplos de relaciones artísticas entre Antequera (Oaxaca) y Santiago de Guatemala en el siglo xvı", Cuadernos. Revista de Ciencias Sociales del Sur, núm. 2I (2005): 6.

21. Berlin, Historia de la imaginería, I64-167.

22. Berlin, Historia de la imaginería, $\mathbf{1 6 6 .}$ 
DOI: https://doi.org/10.22201/iie.18703062e.2021.118.2746

NUEVAS NOTICIAS SOBRE ALFONSO DE PINOS

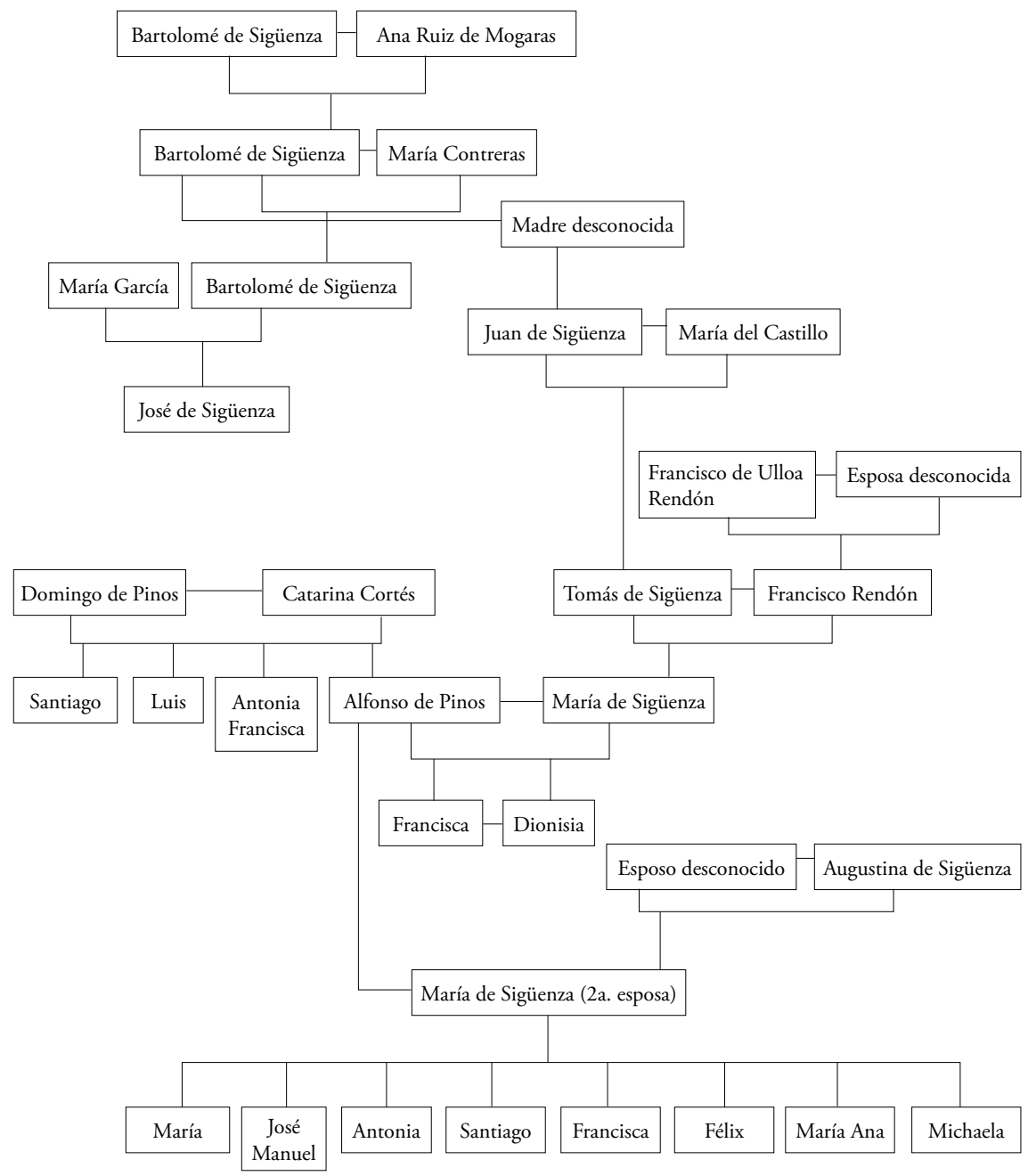

I.Genealogía de Tomás de Sigüenza y Alfonso de Pinos. Elaborada por Edén Zárate. 


\title{
DOI: https://doi.org/10.22201/iie.18703062e.2021.118.2746
}

\author{
236 EDÉN ZÁRATE
}

de Francisco de Ulloa Rendón-y procrearían a María de Sigüenza, a quien Alfonso de Pinos haría su esposa en I705.

\section{El aprendizaje}

No pretendo repetir lo escrito acerca de Tomás de Sigüenza ${ }^{23}$ y su labor en varias iglesias de Oaxaca; me interesa destacar cómo se dio su relación con Alfonso de Pinos, ya que, si bien queda patente por el hecho de que contrajo matrimonio con su hija María de Sigüenza, también coincide que ambos realizaron trabajos para la catedral oaxaqueña.

No se conoce aún la escritura de aprendizaje de Pinos, sin embargo, se puede inferir que el proceso de instrucción en los oficios de carpintero,

23. Algunos autores que han escrito sobre Tomás de Sigüenza y sus obras en Oaxaca son: Xavier Moyssén "Escultura barroca de Oaxaca", Caminos de México, núm. 38 (1963); Heinrich Berlin "Oaxaca: la iglesia de San Felipe Neri. Noticias de artífices", Archivo Español de Arte (Madrid: 1983); Guillermo Tovar y Teresa, Repertorio de Artistas, t. II (México: Fundación Cultural Bancomer, 1995); y Fátima Halcón, "Noticias sobre Tomás de Sigüenza en Oaxaca”, Acervos, Boletín de los Archivos y Bibliotecas de Oaxaca, núm. I (1996) y "La escultura de los retablos del barroco", Historia del arte en Oaxaca, t. II (México: Gobierno del Estado de Oaxaca, 1997). A partir de 1708 se pierde el rastro de Sigüenza en la ciudad de Oaxaca. Halcón, "Noticias sobre Tomás de Sigüenza”, I3, recupera una pista de él en la Ciudad de México, pero menciona que "dice ser natural de los reinos de Castilla", por lo que puede tratarse de un homónimo. Nuestro Tomás de Sigüenza, de acuerdo con lo que vengo apuntando, fue hijo de Juan de Sigüenza y María del Castillo, y en 1687 tenía 20 años, por lo que no pudo ser originario de los reinos de Castilla, véase Berlin "Historia de la imaginería", I66. Aunque he localizado dos noticias relativas a un carpintero llamado Tomás de Sigüenza, no es posible afirmar que se trate del mismo; éste trabajó para la Catedral de México en I729, cuando falleció el maestro carpintero Juan Ignacio de Espinosa, encargado de poner en Semana Santa los candiles, tenebrario, matraca y el candelero del cirio pascual; para ello hizo un contrato en el que se obligó a realizar dichas tareas, además de darles mantenimiento por tiempo de nueve años y salario anual de cuatrocientos pesos. Véase: Archivo General de Notarías de la Ciudad de México, escribano: Francisco Dionicio Rodríguez, notaría: 576, vol. 3952, I6 de abril de I728, ff. I47v-150v; y Archivo del Cabildo Catedral Metropolitano de México, Actas de cabildo, vol. 3I, 26 de abril de 1726, f. 220. Cabe aclarar que desconozco la razón por la cual Halcón lo llamó "Ildefonso" y no Alfonso, como rubricó en los conciertos de obra que realizó. Si bien es cierto que ambos nombres comparten su raíz germánica, no significan lo mismo y para las fechas en que trabajó Pinos, quedaba clara la diferenciación de los nombres. Es sólo en el testamento de nuestro artista, en el que el escribano registró los nombres "Sant Yago e Ildephonso de Pinos"; no obstante, en su rúbrica queda bastante claro "Alfonso de Pinos". 
ensamblador, tallador y dorador, se dio dentro de su círculo familiar. Si bien, ni su padre ni sus hermanos practicaban estos oficios, debió aprenderlos con Jerónimo y Jacinto de Pinos con quienes, por el mismo apellido, probablemente tuvo un vínculo familiar. ${ }^{24}$ Jerónimo era esposo de María de Verganza, tuvieron una hija llamada Nicolasa Tomasa quien contrajo matrimonio el 20 de febrero de 1708 con el carpintero Antonio Delgado; ${ }^{25}$ Jerónimo era ensamblador y se contrató con el alférez Manuel Sánchez el 2 de julio de I69I para hacer un retablo de madera dedicado a san José, de siete varas de alto con división de tres cuerpos y tres calles, con ocho columnas. ${ }^{26}$ Jacinto, probablemente fue hijo de Jerónimo y María, y el 24 de marzo de 1724, junto con Joaquín Curiel y José Mateo de Robles, se obligaron a hacer para los principales y naturales del pueblo de San Juan Guelache, sujeto a la villa de Etla, un retablo de madera en blanco, con cuatro cuerpos, dieciocho columnas, con cinco calles de planta y catorce entrecalles de lienzo y el nicho principal de once varas y tres cuartos de alto con diez varas de ancho; dicha obra sería entregada en diez meses. ${ }^{27}$ Contrajo segundas nupcias el 28 de enero de I7II con la doncella española Josefa de Torres, de quien se desconoce a sus padres. ${ }^{28}$

Al ejercer el mismo oficio, no cabe duda de que, tanto Jerónimo de Pinos como Tomás de Sigüenza, se conocieron. En algún momento Jerónimo, acompañado de su aprendiz Alfonso, debió visitar el taller de Tomás y ahí pudo conocer a María. Después de contraer nupcias debió continuar su aprendizaje en el taller de su suegro en la ciudad de Oaxaca; con los avances en el aprendizaje, pudo trabajar con él y recomendarlo para realizar algunas obras en aquella ciudad.

\section{Las primeras obras}

Los primeros ańos de su vida matrimonial debieron ser económicamente difíciles, pues de acuerdo con su memoria testamentaria, durante ese

24. En mi búsqueda documental no localicé ningún indicio que permitiera establecer que Jerónimo de Pinos fuera hermano de Alfonso, como lo indica Halcón, salvo los mencionados en su testamento. Véase: Fátima Halcón, "Oaxaca: noticias de artistas", I44.

25. APSMdo, Matrimonios, vol. 3, I70I-I708, f. 202.

26. Ahneo, escribano: Diego Díaz Romero, lib. I67, 2 de julio de I69ı, f. I62.

27. Loc. cit., escribano: José de Araujo, lib. I26, 24 de marzo de I724, f. I9ov.

28. Jacinto se había casado con Josefa Rodríguez Manzano, quien murió en 1706, fue sepultada en la iglesia de San Agustín, véase: Apsmdo, Matrimonios, vol. 4, I708-1717, f. 85. 


\section{DOI: https://doi.org/10.22201/iie.18703062e.2021.118.2746}

matrimonio "no llevó bienes algunos de ella, ni los trajo ni los hubo, ni los tuvimos en el tiempo de doce [sic] ańos que fuimos casados". ${ }^{29}$ El proceso de aprendizaje comenzó por el oficio de carpintero y ensamblador, lo que le permitió trabajar en las casas del canónigo Henrico Angulo entre I7I4 y 1723. De acuerdo con Berlín:

Alfonso de Pinos, maestro ensamblador y carpintero, vecino, manifestó que [Angulo] encargó a este testigo la labranza de toda la madera que en reedificar dichas casas entró. La cual con efecto labró este testigo en las mismas casas, suministrándole dicho doctor las maderas... y que vio dicho Doctor en la reedificación de dichas casas, asistió personalmente y disponiendo de cosas. ${ }^{30}$

Tendría que esperar hasta el 30 de diciembre de I723, cuando el alférez Juan Francisco Gutiérrez, vecino y del comercio de Oaxaca, y José Pinelo, mayordomo de la cofradía de Nuestra Señora de las Nieves, concertaron con Pinos la elaboración en blanco del retablo mayor de la iglesia de Nuestra Señora de las Nieves. Este templo se encuentra en el centro histórico de la ciudad de Oaxaca (fig. 2) y se pueden distinguir tres etapas en su construcción; la primera se remonta hasta el siglo Xvi cuando los jesuitas Diego López y Juan Rogel fundaron la Compañía de Jesús en Oaxaca en $1576 .{ }^{31} \mathrm{Al}$ mismo tiempo, los jesuitas edificaron su centro de enseñanza con fondos que donó el deán de la catedral, don Juan Luis Martínez. El colegio tuvo funciones hasta 1596 debido a que el capital que sustentaba al colegio fue usado para construir el convento de la Compañía. ${ }^{32}$ Sin embargo, la capilla interior del colegio se abrió al público; de acuerdo con nuestra fuente, se comenzó a construir en 158 I y se bendijo en 1585 bajo la advocación de Santa María la Mayor, también conocida como Nuestra Señora del Popolo. ${ }^{33}$

29. AHneo, escribano: Manuel Álvarez de Aragón, núm. de inv. Io, I de diciembre de I735, ff. I68-169v.

30. Berlin, "Oaxaca, la iglesia de San Felipe Neri”, 50.

31. Departamento de Estudios Históricos e Investigación, "Restauración del Templo de Nuestra Señora de las Nieves, Oaxaca. Memoria de los Trabajos de Intervención”, La Gaceta del Instituto del Patrimonio Cultural, núm. 2I (enero-abril, 20I2): 5.

32. Departamento de Estudios Históricos e Investigación, "Restauración del Templo de Nuestra Señora de las Nieves, Oaxaca”, 5.

33. Departamento de Estudios Históricos e Investigación, "Restauración del Templo de Nuestra Señora de las Nieves, Oaxaca”, 5. 
2. Fachada de la iglesia de Nuestra Señora de las Nieves,

Oaxaca. Foto: Edén Zárate. Secretaría de Cultura-INAH-MÉx. "Reproducción autorizada por el Instituto Nacional de Antropología e Historia”.

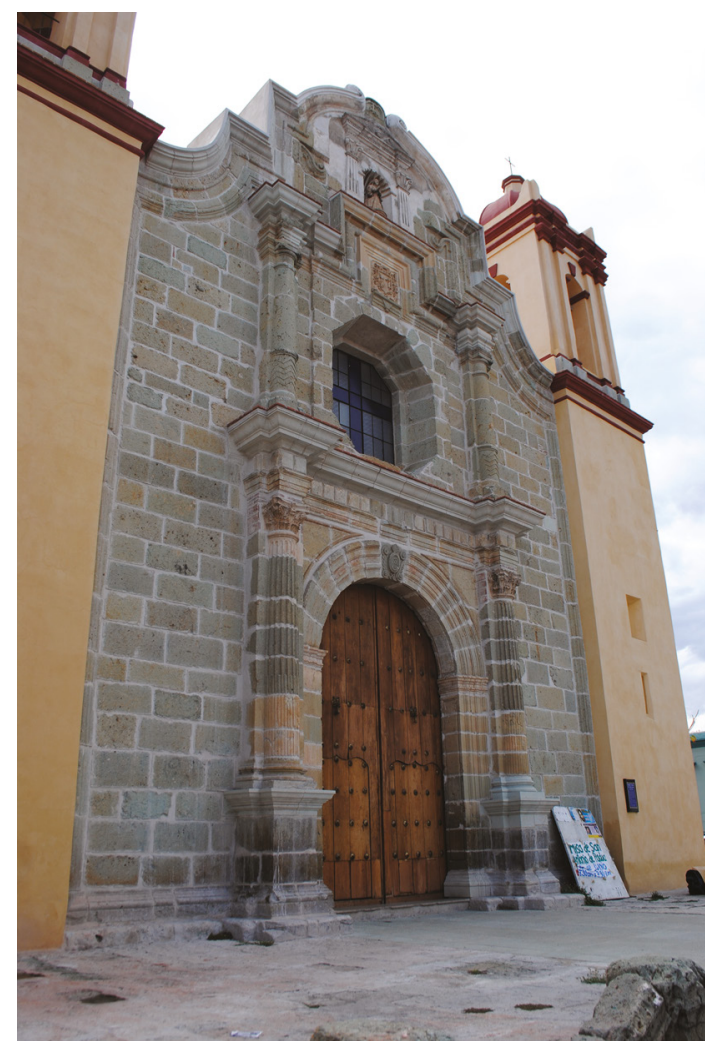

En el siglo XVII comenzó una segunda etapa constructiva del edificio; fue necesario agrandarla para "el servicio de vecindario". Durante este siglo el templo se conoció como Nuestra Señora del Popolo por la imagen que dejaron sus fundadores, era una copia de la original que se encuentra en Roma. ${ }^{34}$ Por causas que se desconocen, en esta misma etapa fue cuando la iglesia quedó bajo la advocación de Nuestra Señora de las Nieves. ${ }^{35}$ De acuerdo con la tradición, sabemos que esta Virgen se le apareció al papa san Liberio (352-366) un 5 de agosto, después de una tormenta que hizo que el monte Esquilino se cubriera

34. "Restauración del Templo de Nuestra Señora de las Nieves", 5

35. Carlos Velasco Pérez, Oaxaca, Patrimonio cultural de la humanidad (Oaxaca: Colección Glifo del Gobierno del Estado, 1991), 75 . 


\section{DOI: https://doi.org/10.22201/iie.18703062e.2021.118.2746}

240

EDÉN ZÁRATE

de nieve - fenómeno muy raro, pues en Roma, agosto es uno de los meses más calurosos - indicándole el lugar exacto en dicho monte para que se le construyera su templo. ${ }^{36}$

Los sismos de 1696 y I72I dañaron el templo y su reconstrucción tuvo que esperar la llegada de Miguel Anselmo Álvarez de Abreu, obispo auxiliar de Puebla y titular de Oaxaca (entre 1765 y 1774); fue durante su gestión cuando se decidió la demolición y reconstrucción, hecho que ocurrió en diciembre de 1765..$^{37}$ La devoción de Miguel Anselmo hacia la imagen de Nuestra Señora de las Nieves, queda patente en su última voluntad, en ella menciona que le ha tenido "muy particular afecto y devoción" ${ }^{38}$ por lo que no dudó en dejar una buena parte de su fortuna para la reconstrucción de la iglesia.

Regresando a nuestro artífice, Alfonso de Pinos, en 1723, debía elaborar el retablo mayor para dicha iglesia y de acuerdo con la escritura, éste debía ser:

de quince varas de alto y diez de ancho, con la misma planta y fábrica que contiene el del altar mayor de la iglesia del convento de San Agustín de dicha ciudad, excepto santos de bulto y cajas. ${ }^{39}$

Por ello cobraría I,OOo pesos y lo entregaría en diez meses, contados a partir del I de enero de $1724 .{ }^{40}$ El alférez, por su parte, se obligó a entregarle el dinero y el "avío necesario", para que no se atrasara la obra. El retablo debía ser, como se dijo líneas arriba, de la misma "planta y fábrica" que el del altar mayor de la iglesia del convento de San Agustín. ${ }^{41}$ La escritura permite establecer que la carrera de Pinos comenzaba a ascender en los oficios del tallado y ensamblado, pues dejó la obra en blanco; los contratantes se aseguraron de que quien continuara la obra, debía hacerlo con la misma calidad que le había dedicado Pinos. Lamentablemente, lo poco que se conserva en la iglesia de Nuestra

36. Velasco Pérez, Oaxaca, Patrimonio cultural de la humanidad.

37. Pablo Amador Marrero, "Mecenazgo artístico del obispo canario Miguel Anselmo Álvarez de Abreu en Oaxaca. La iglesia de Nuestra Señora de las Nieves", La Gaceta del Instituto del Patrimonio Cultural, núm. 2I (enero-abril, 20I2), "Sección: Arte y Expresión, Oaxaca, México", 17.

38. Amador Marrero, "Mecenazgo artístico del obispo canario", i8.

39. Ahneo, escribano: José Manuel Álvarez de Aragón, núm. de inv. 34, 30 de diciembre de I723, ff. 499-50I.

40. AHneo, escribano: José Manuel Álvarez de Aragón.

4I. AHneo, escribano: José Manuel Álvarez de Aragón. 
3. Retablo mayor neoclásico de la iglesia de Nuestra Señora de las Nieves, Oaxaca. No se conserva nada del que realizó Alfonso de Pinos. Foto: Edén Zárate. Secretaría de Cultura-INAH-MÉx. "Reproducción autorizada por el Instituto Nacional de Antropología e Historia”.

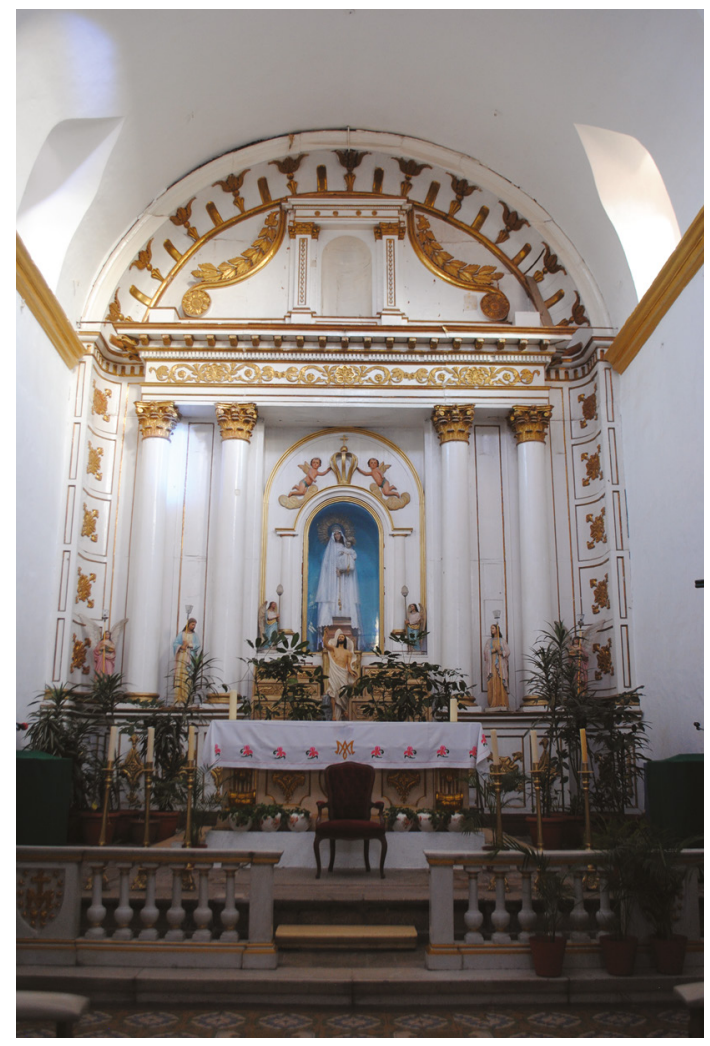

Señora de las Nieves, no permite saber si algo de ello pertenece al retablo que en aquel momento elaboró Pinos (fig. 3).

\section{Obras en la catedral oaxaqueña}

Los trabajos en la casa del canónigo Henrico Angulo y la hechura del retablo de Nuestra Señora de las Nieves le abrieron las puertas para trabajar en la catedral de Oaxaca. Así, a partir del mes de mayo de 1726 aparece haciendo algunas obras de carpintería para dicho recinto, entre ellas la elaboración de dos puertas y ventanas para la vivienda del sacristán mayor; ${ }^{42}$ la hechura y el

42. Archivo Histórico de la Arquidiócesis de Oaxaca (en adelante: AHAO), Contaduría, caja I88 (I725-I729), exp. O5 (I726), ff. 56v-57. 


\section{DOI: https://doi.org/10.22201/iie.18703062e.2021.118.2746}

maderaje para el esquilón nuevo; ${ }^{43}$ la reparación de los facistoles y atriles; ${ }^{44}$ entre otras obras menores. Para 1729 su labor dentro de la catedral comienza a crecer, pues realizó la compostura y colocación del monumento de Semana Santa, el lavatorio, la elaboración de un estante para los libros de coro y unas bancas para la iglesia. ${ }^{45}$

En la mayoría de los casos los cabildos de las catedrales novohispanas nombraron a sus maestros de obras de manera anual; al revisar las Actas de Cabildo de la catedral oaxaqueña, no localicé el nombramiento de Pinos como carpintero de la catedral, esto me lleva a pensar que el recinto debió tener algunos problemas económicos que no permitieron nombrar a nuestro artífice con un salario anual, por lo cual el cabildo decidió pagarle por obra realizada.

El 3I de mayo de i73o el deán y cabildo de la catedral oaxaqueña dispuso que para la consagración del obispo fray Francisco Calderón

se dé cuenta de todo lo que se hubiere de ejecutar a Su Señoría Ilustrísima para que disponga lo que fuere servido y se determine la puerta por donde ha de entrar, altar, tablados y demás necesario, y el modo que disponga esta Santa Iglesia para su consagración..$^{46}$

El encargado de dicha obra fue el maestro ensamblador Alfonso de Pinos; las labores que realizó, los materiales usados y su costo, fueron los siguientes:

Primeramente, por quitar y poner la crujía

IO ps. 4

Iten, por llevar y traer las maderas que presté para la consagración

2 ps. 4

Iten, por un peso de clavos

I ps.

Iten, por quitar ese tablado

I2 ps.

Iten, por colgar la iglesia

3 ps.

Iten, por el costo que tuvo de peones y oficiales de poner y quitar el monumento

I5 ps.

Iten, por poner y quitar el tablado en que se recibió su señoría ilustrísima, fuera de costo de clavos, petates, carrizos y mecates

Por doce reales de clavos

24 ps.

I p. 4

43. AHaO, Contaduría, f. 58.

44. анао, Contaduría, f. 59.

45. AHAO, Contaduría, caja: I88 (1725-1729), exp. II (I728), ff. 68v-69v.

46. AнаO, serie: Actas de Cabildo, lib. 4, f. 340v. 
Por dos pesos de mecates

Por diez y ocho reales de petates

Iten, por seis reales de carrizo

Iten, por mi trabajo y asistencia

$$
\begin{array}{r}
2 \text { ps. } \\
2 \text { ps. } 4 \\
\text { ps. } 6 \\
25 \text { pesos }^{47}
\end{array}
$$

El costo del tablado para el recibimiento de dicho arzobispo fue de "79 pesos" [sic], que fueron cubiertos en su totalidad el I4 de julio de ese año..$^{48}$

La presencia del ensamblador, que me ocupa en la catedral oaxaqueña, fue cada día más notoria y la relación con su cabildo era excelente; no dudaban de su maestría, pues cuando solicitó licencia para colocar en el altar —en el que se ponía a la Virgen de Nuestra Señora de la Soledad - una "urna de madera dorada y ochavada, de vidrieras, para el mayor aseo y culto de la Señora" no lo dudaron, sólo propusieron que las llaves de dicha urna las tuviera una persona de confianza y que "el arme y desarme de dicha urna, la realizará Pinos". 49

Ahora bien, la obra más importante dentro de ese recinto sería el dorado del altar de los Reyes, que comenzó el mes de diciembre de 173I, obra que debería estar lista para la consagración de dicho edificio, hecho que ocurrió el domingo I2 de julio de 1733 durante el obispado del "ilustrísimo y reverendísimo maestro don fray Francisco Antonio de Santiago y Calderón, del real Militar Orden de Nuestra Señora de la Merced", tal y como reza la cartela conmemorativa colocada en una pilastra de una de las naves laterales de la catedral (fig. 4).

De acuerdo con Fátima Halcón, uno de los retablos que se hicieron para la consagración de la catedral de Oaxaca y que se conservaba aún en el año de I865, le fue encargado a "Ildefonso de Pinos" en 1726 y por él se le pagó:

mil ochocientos pesos sobre un concierto total de 3,229 pesos, que terminó de cobrar en 1734. Este retablo, llamado de los Reyes, admirado por su magnificencia y esplendor, ocupaba todo el testero de la nave central del templo..$^{50}$

A diferencia de lo que escribe esta autora, pienso que esta obra no pudo iniciar en la fecha arriba citada, pues los datos de la serie de Contaduría de la catedral oaxaqueña no permiten verificarlo. Se sabe por dichos registros que el primer

47. AнAO, serie: Contaduría, caja I89 (I729-I73I), exp. 03 (I730), f. s/f.

48. AHAO, serie: Contaduría.

49. La licencia de donación la realizó el 20 de junio de I730, véase AHAO, Actas de Cabildo, lib. 4 , ff. $343 \mathrm{v}-344$.

50. Halcón, "La escultura de los retablos del barroco", 93. 


\section{DOI: https://doi.org/10.22201/iie.18703062e.2021.118.2746}

244

EDÉN ZÁRATE

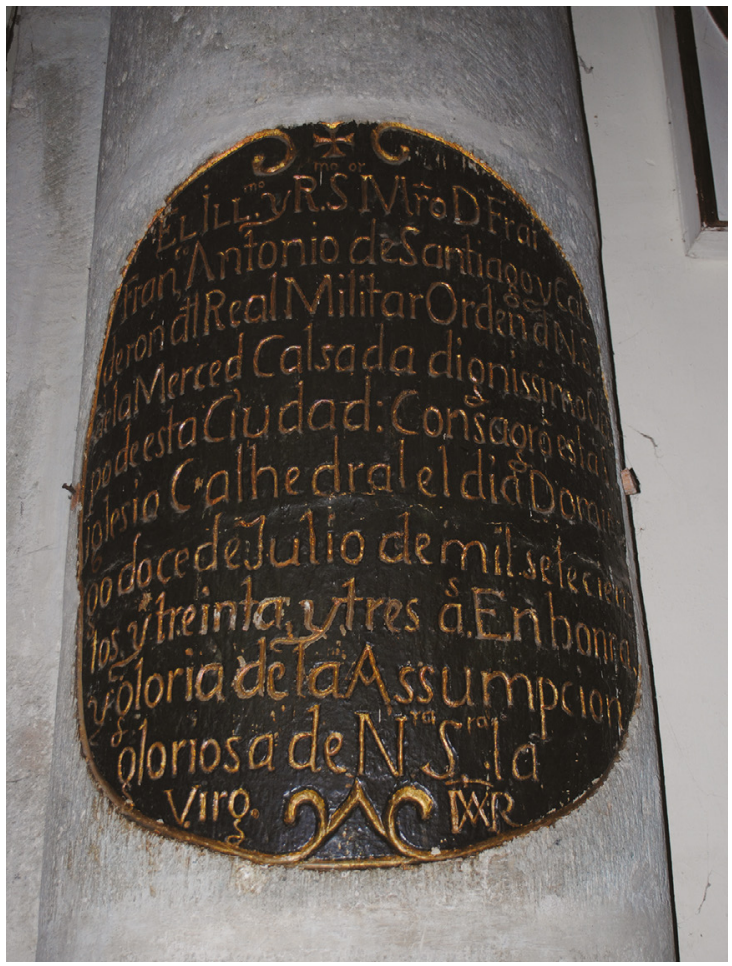

4. Cartela conmemorativa de la consagración de la Catedral de Oaxaca. Foto: Edén Zárate.

pago para el dorado del altar de los Reyes se realizó el 3I de diciembre de I73I cuando el cabildo catedralicio mandó pagar

Ioo pesos a cuenta, de lo que ha de llevar de dorar el retablo del altar de los reyes; con dichos Ioo pesos hacen 500: 300 pagados por los señores claveros don Diego de las Heras y licenciado Juan de Leyva Cantábrana, y los 200 que dio el licenciado Lora y Mexía. ${ }^{\text {SI }}$

Es decir, que el pago para iniciar los trabajos fue de 500 pesos, que corrieron a cargo de la Fábrica Material de la iglesia. La obra debió concluirse antes de la consagración del recinto catedralicio y el obispo fray Francisco Antonio Santiago y Calderón, debió contribuir al pago, pues el 9 de octubre de 1734 la Fábrica Material le abonó al obispo “2,249 pesos y 2 reales que se le entregaron a

5I. AHAO, Contaduria, caja I89 (I729-I73I), exp. O2 (I73I), f. 7I. 
Pinos para dorar el retablo de Los Reyes; y aunque consta por los recibos del dicho Pinos ser 3,249 pesos y 2 reales, no se cargan a la fábrica más que la cantidad arriba dicha”. ${ }^{52}$ Ese mismo día los contadores pagaron 20 pesos más al ensamblador, con lo que liquidaron el total de la obra que se había concertado en 3,800 pesos. ${ }^{53}$

Paralelamente al dorado del altar de los Reyes, Pinos realizó otras obras: algunos reparos para la capilla de Nuestra Señora de Guadalupe, por los que le pagaron 43 pesos y cuatro reales y medio el 26 de junio de 1732 ; $^{54}$ la compostura de la campana y una mesa para el altar del Perdón, dos bancas para la familia de Su Ilustrísima, las puertas para tapar el órgano y la obra de los espejos grandes, obras que le fueron pagadas el 29 de octubre de ese año $0^{55}$ y por las que recibió 98 pesos y dos tomines. Para 1734 labró y compró una docena de tablas y "una mesa de altar para el de los reyes" 56 . Además, compuso "catorce sillas e hizo un sagrario de madera". ${ }^{57}$

\section{Los vaivenes económicos}

Los primeros trabajos de Alfonso de Pinos en la catedral oaxaqueña fueron obras de carpintería, mientras trabajó en ésta no se sabe si realizó otras fuera del ámbito catedralicio ¿Qué pudo influir para que su labor hasta ese momento fuera reducida? Tal vez el conflicto que tenía con los carpinteros, doradores, ensambladores y estofadores de aquella ciudad, pues a pesar de que no había gremio ni veedor, no le permitían ejercer su oficio, con el pretexto de no estar examinado; ${ }^{58}$ para ello, en junio de 1731, solicitó al virrey que lo dejaran trabajar, pues debía mantener a su familia. Además, las obras que le encargaban las entregaba de manera puntual y perfectamente bien terminadas, según y como se convenía en el precio; por lo que el virrey ordenó al corregidor de la ciudad de Antequera, que al no haber gremio de carpinteros, escultores y doradores, no le impidieran ejercer su oficio, bajo pena de 20 pesos y la suspensión de su

\footnotetext{
52. AнаO, Contaduría, caja I9I (I733-I734), exp. 03, f. 4 Ov.

53. AHAO, Contaduria, caja I9I (1733-1734), exp. 03, f. 4 Ov.

54. AHAO, Fábrica Material, caja 0040 (I7I4-I752), exp. 307, f. 29.

55. AHAO, Contaduría, caja I9O (I73I-I733), exp. oI, f. $52 \mathrm{~V}$.

56. AHaO, Contaduría, caja I9I (I733-1734), exp. 03, f. $39 \mathrm{v}$.

57. AHaO, Contaduría, caja I9I (I733-I734), exp. 03, f. 4I.

58. Archivo General de la Nación, General de parte, vol. 28, exp. 69, f. 6ov.
} 


\section{DOI: https://doi.org/10.22201/iie.18703062e.2021.118.2746}

246

EDÉN ZÁRATE

oficio; se le hace saber también lo útil y conveniente que sería crear ese gremio u otros en esa ciudad; Pinos pudo continuar ejerciendo su labor. ${ }^{59}$

A pesar de este conflicto, la situación económica de Pinos — de quien para estas fechas su primera esposa ya había fallecido y había contraído segundas nupcias- mejoró notablemente, pues pudo comprar y vender esclavos, que fueron utilizados como sirvientes en su taller y en su vivienda. Así el i6 de agosto de 1724 Pinos, maestro ensamblador, vendió al alférez don José de Echeverría una mulata llamada Juana María de I8 años; poco después la vendió en 255 pesos de oro común. ${ }^{60} \mathrm{El}$ I5 de noviembre de 1728 compró otro esclavo ${ }^{61}$ en 225 pesos de oro común. Años después lo vendería en la misma cantidad. ${ }^{62}$ Sus finanzas le permitieron seguir comprando esclavos.

\section{El final de los días y las obras inconclusas}

Dos obras quedaron sin concluir: la primera fue un colateral para la iglesia de San José que concertó con el canónigo Diego de las Heras; la razón por la que no terminó la obra fue que dicho canónigo no le dio ioo pesos que requería para los materiales y finalizar la obra. ${ }^{63}$ Se desconoce la forma que debía tener el retablo; debemos esta noticia a su testamento en el que, para evitar algún reclamo posterior, lo dejó asentado.

La segunda fue la "obra y manufactura del dorado" de cuatro colaterales para la Orden Tercera de San Francisco, que concertó el 4 de junio de 1735 con Ignacio de Yrizar y don Diego Antonio Larrainzar, ministro y coadjutor, sucesivamente, de la capilla de dicha Orden: el primero de ellos dedicado a Nuestra Señora de Aranzazú y patrocinado por Yrizar; el segundo a san Diego y pagado por Larrainzar; el tercero a Jesús Nazareno y el cuarto al Ecce Homo,

59. Archivo General de la Nación, General de parte, vol. 28, exp. 69, f. 6ov.

6o. AHneo, escribano: José Manuel Álvarez de Aragón, núm. inv. 35, I6 de agosto de I724, ff. $340 \mathrm{OV}-34 \mathrm{IV}$.

6I. AHneo, escribano: José Manuel Álvarez de Aragón, núm. inv. 40, I5 de noviembre de I728, ff. 386-387.

62. ahneo, escribano: José Manuel Álvarez de Aragón, núm. inv. 44, 28 de septiembre de I73I, ff. 434-435.

63. Ahneo, escribano: José Manuel Álvarez de Aragón, núm. de inv. Io, 4 de junio de I735, f. 169 . 


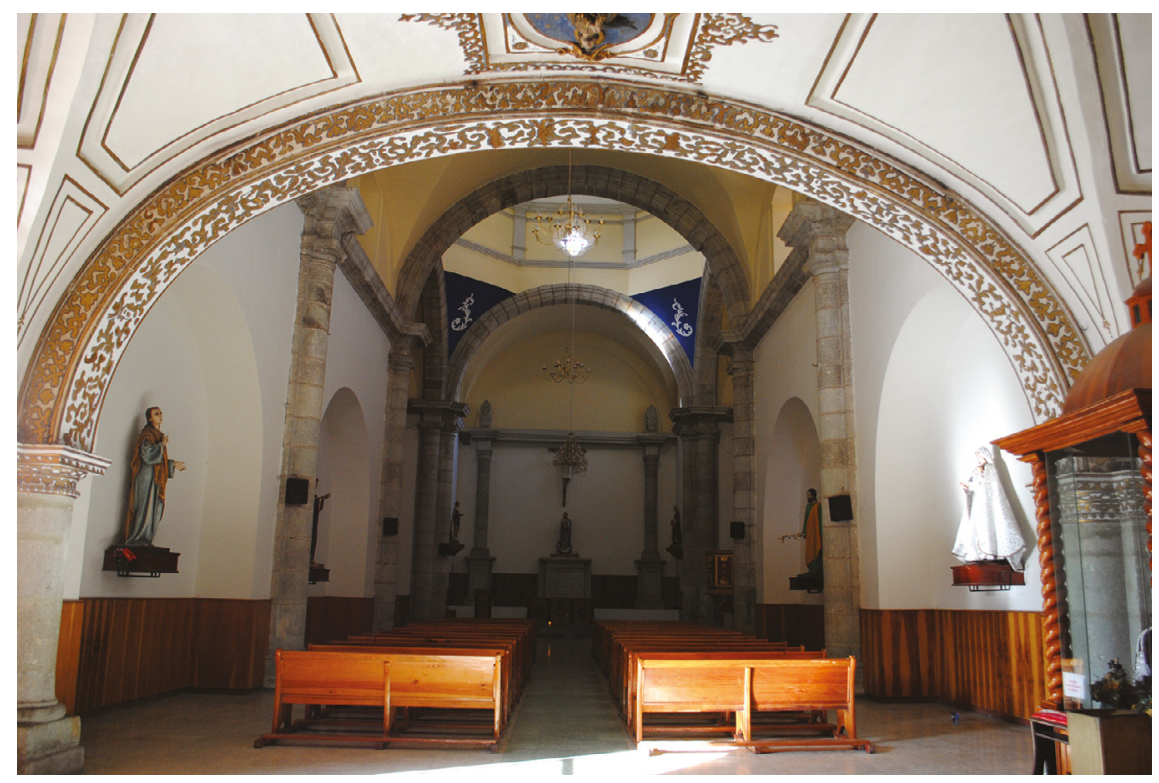

5. Vista del interior de la capilla de la Tercera Orden de San Francisco en Oaxaca. Se observan las cuatro hornacinas en las que estuvieron los colaterales que debía fabricar y dorar Alfonso de Pinos. Foto: Edén Zárate. Secretaría de Cultura-INAH-MÉX. "Reproducción autorizada por el Instituto Nacional de Antropología e Historia”.

estos dos últimos pagados por un "bienhechor y devoto de [esas] santísimas efigies" (fig. 4).

Toda la obra costaría I,I60 pesos: 800 por los dos primeros y 360 pesos por los dos últimos, y corrían a su cuenta los materiales necesarios que incluían "los libros de oro" que en los cuatro colaterales se gastaran. ${ }^{64}$ Quedó asentado que el oro que se utilizaría debía ser regulado a ocho reales y medio por libro; además debía ser "oro limpio, sin mezcla de esmalte ni otro ingrediente alguno". Se estableció un pago adelantado de 160 pesos y lo demás se entregaría semanalmente para el pago de oficiales “y mantenimiento"; lo demás quedaría liquidado en cuatro meses, contados a partir de la fecha de la escritura, al finalizar la obra.

Desde 1714, cuando trabajó en las casas del canónigo Henrico Angulo, su labor en la iglesia de Nuestra Señora de la Nieves y en la catedral oaxaqueña,

64. AHneo, escribano: José Manuel Álvarez de Aragón, núm. de inv. 50, ff. I68v-I7I. 
permite ver cómo este artífice venía creciendo como carpintero, ensamblador y dorador. Hasta el verano de 1735 los colaterales de la iglesia de la Tercera Orden de San Francisco representaban su reconocimiento fuera del ámbito catedralicio; sin embargo, el 9 de mayo de 1736, el escribano José Manuel Álvarez de Aragón se vio forzado a cancelar la escritura, esto a petición de Diego Antonio Larrainzar. El bachiller Santiago de Pinos, hermano de Alfonso, devolvió ese día 230 pesos y un real que le habían pagado durante el transcurso de la obra; supongo que el ensamblador debió enfermar poco después de que firmó el contrato; pudo haber realizado algunos avances y como parte del adelanto, entregaron 70 pesos. Poco a poco su salud se fue deteriorando hasta que le fue imposible continuar con la obra. La muerte lo alcanzó ese invierno.

El hallazgo del testamento de Alfonso de Pinos, junto con la revisión de los libros sacramentales que resguarda el Archivo de la Parroquia del Sagrario Metropolitano de la Diócesis de Oaxaca, permiten aportar y rectificar los datos biográficos, tanto de Pinos como de sus familiares: quiénes fueron sus padres, hermanos, esposas e hijos, así como el vínculo familiar con Tomás de Sigüenza. La consulta de las Actas Capitulares de la catedral de Oaxaca y de los documentos notariales nos da la oportunidad de conocer el trabajo realizado dentro y fuera del ámbito catedralicio: contratantes, costos, tiempos de entrega; obra de la que, lamentablemente, nada se conserva. is

N.B. Esta investigación se realizó en el marco del proyecto "Los talleres de pintores y escultores novohispanos en Oaxaca. Investigación documental y catalogación de la obra”, que estuvo bajo la dirección de Elisa Vargaslugo, a quien dedico este texto. 